\title{
Ssssneaky, Pesssky, Ssspeciess! ${ }^{1}$
}

\author{
Charles Jacoby, Nanette Holland, and Debbi Berger ${ }^{2}$
}

\section{UF | FLORIDIDA IFAS Extension}

The Institute of Food and Agricultural Sciences (IFAS) is an Equal

Opportunity Institution authorized to provide research, educational information and other services only to individuals and institutions that function with nondiscrimination with respect to race, creed, color, religion, age, disability, sex, sexual orientation, marital status, national origin, political opinions or affiliations. For more information on obtaining other extension publications, contact your county Cooperative Extension service.

U.S. Department of Agriculture, Cooperative Extension Service, University of Florida, IFAS, Florida A. \& M. University Cooperative Extension Program, and Boards of County Commissioners Cooperating. Larry Arrington, Dean.

\section{Copyright Information}

This document is copyrighted by the University of Florida, Institute of Food and Agricultural Sciences (UF/IFAS) for the people of the State of Florida. UF/IFAS retains all rights under all conventions, but permits free reproduction by all agents and offices of the Cooperative Extension Service and the people of the State of Florida. Permission is granted to others to use these materials in part or in full for educational purposes, provided that full credit is given to the UF/IFAS, citing the publication, its source, and date of publication.

\footnotetext{
${ }^{1}$ This document is CIR1511, an Activity in an Invasive Species Curriculum (CIR1496), and it is reprinted by permission of the Tampa Bay Estuary Program and The Florida Aquarium. Original EDIS publication date: January, 2007. It was supported by the Tampa Bay Estuary Program, the Florida Aquarium, the Department of Fisheries and Aquatic Sciences of the University of Florida, and the National Sea Grant College Program of the National Oceanic and Atmospheric Administration (NOAA), U.S. Department of Commerce, under NOAA Grant No. NA 16RG-2195. Visit the EDIS Web Site at http://edis.ifas.ufl.edu.

${ }^{2}$ Charles Jacoby, Assistant Professor, Department of Fisheries and Aquatic Sciences, Cooperative Extension Service, Institute of Food and Agricultural Sciences, University of Florida, Gainesville, 32611; Nanette Holland, Public Outreach Coordinator, Tampa Bay Estuary Program, 100 8th Avenue S.E., MS I-1 / NEP, St. Petersburg, FL 33701; Debbi Berger, Vice President of Education, The Florida Aquarium, Inc., 701 Channelside Drive, Tampa, Florida, 33602.
} 
This page was intentionally left blank. 


\section{Invasive Species \\ Series
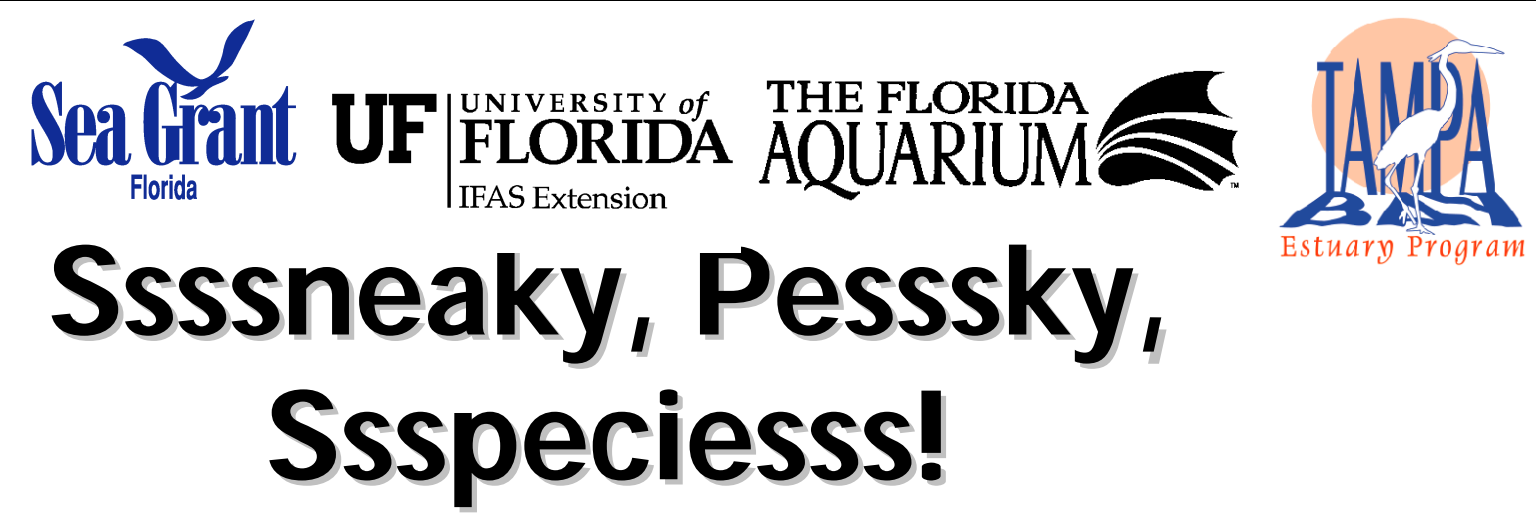

Sne ak Pe eK

Students will be introduced to the concepts and issues surrounding invasive species. $\mathcal{A}$ potential Florida invader is the Brown Tree Snake, Boiga irregularis. Students will explore how this resourceful snake wiped out many native species on Guam and the potential harm it could cause here in Florida. This activity incorporates critical thinking, predicting, and math skills.

\section{Objectives:}

Students will...

- Identify the damage an invasive species can inflict on an environment.

- D emonstrate understanding of the spread of an invasive species in a particular area.

- Model the effects the Brown Tree Snake can have on native species.

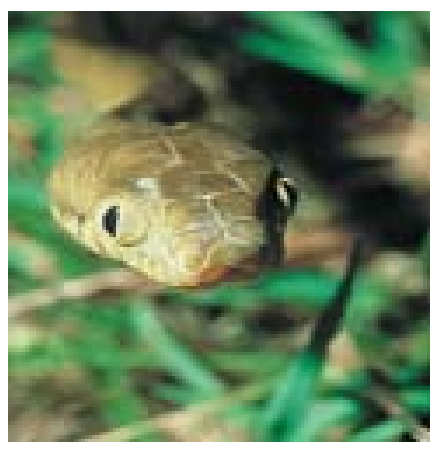

\section{Materials:}

\section{Picture source: NASA}

- 50 snake cut-outs (or $1 / 2$ index cards) per group.

- 200 bird cut-outs (or one-inch squares of paper) per group.

- D ata table (included).

- Graph paper.

\section{Background:}

Invasive species are plants or animals that are not native to a particular area and cause harm by disrupting natural ecosystems. Invasive species may compete with native species for food and living space. A successful invasive species will take over space in which a native species would normally live. It is often difficult to determine exactly what harm a potential invader may 
cause until it is too late. C ase studies have often shown that once an invasive species is established it is virtually impossible to eradicate.

The brown tree snake (Boiga irregularis) is an introduced species on Guam.

The first sightings were in the early 1950s. These snakes became conspicuous throughout central Guam by the 1960 s.

The brown tree snake has become a serious threat due to the absence of natural population controls and availability of vulnerable prey on Guam. The snakes are now causing major ecological and economic problems on the island.

The brown tree snake has virtually wiped out the native forest birds of Guam. Twelve species of birds, some found nowhere else, have disappeared from the island, and several others are close to extinction.

The snakes feed on a wide variety of animals including lizards, birds, and small mammals, as well as bird and reptile eggs. Snakes frequently invade poultry houses, homes and yards to consume domestic poultry, eggs, pet birds and small mammals associated with residential areas. Up to 13,000 snakes per square mile may occur in some forested areas of Guam.

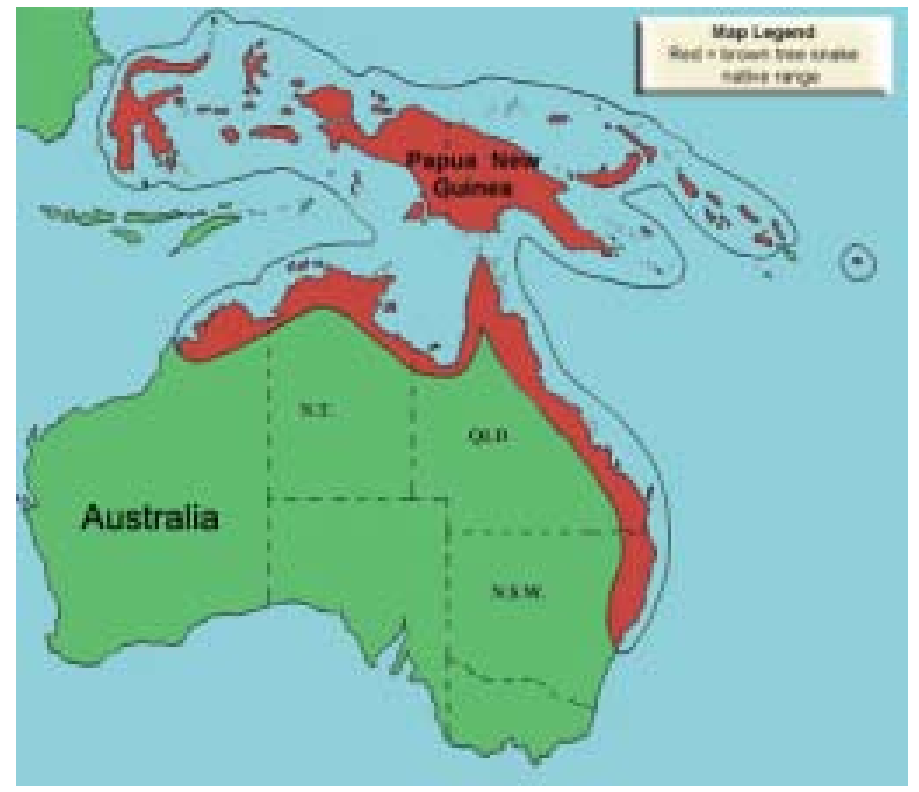

This map from the U.S. Geological Survey shows the native range of the Brown Tree Snake in red/dark gray. 


\section{Procedure:}

1. Provide each group with 200 small squares (or native bird cut-outs) and 50 large squares (or snake cut-outs). Snake cut-outs should be 4-5 times larger than the bird cut-outs.

2. Have students clear their lab table. The table will represent their environment. The table will need to be approximately two feet by five feet long. If using desks, bring four together to make approximately the same amount of space.

3. Students should place 80 of their "birds" on the desk.

4. N ext, have students place their "snake" on the desk trying to touch at least three birds. If the snake touches three birds, it successfully survived this round. Remove the birds that the snake touched before the next round.

5. If at least one snake survives, add another snake for the next round. If no snakes survive, reshuffle the birds and add one snake (a new invader moved in!). For the bird population, add one bird for every two that survived.

6. After each round, students should record the number of snakes and birds in their environment in the data table.

7. Repeat this process until no birds remain or ten rounds are complete.

8. Graph the native bird population over time on the graph provided. 


$$
\begin{aligned}
& 2_{2} \\
& 2_{2}
\end{aligned}
$$




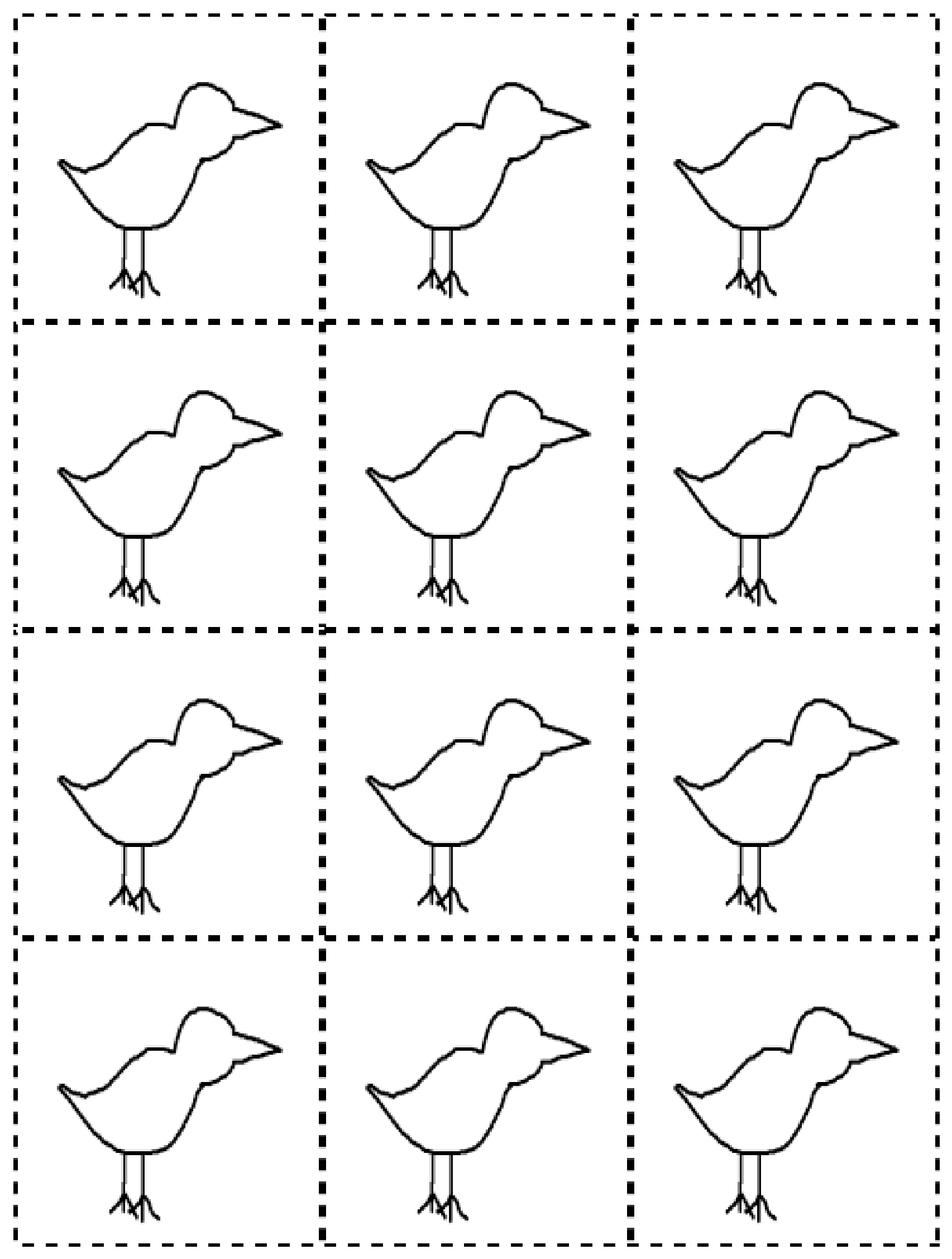

Bird cut-outs 


\section{DATA TABLE}

\begin{tabular}{|c|c|c|}
\hline & Snakes & Birds \\
\hline Snakes \& Birds at start & 1 & 80 \\
\hline Snakes "eating" < 3 birds \& Birds "eaten" & & \\
\hline Surviving snakes $\&$ birds after Round 1 & & \\
\hline Additional Snakes \& Birds for Round 2 & & \\
\hline Snakes \& Birds for Round 2 & & \\
\hline Snakes "eating" < 3 birds \& Birds "eaten" & & \\
\hline Surviving snakes $\&$ birds after Round 2 & & \\
\hline Additional Snakes $\&$ Birds for Round 3 & & \\
\hline Snakes \& Birds for Round 3 & & \\
\hline Snakes "eating" < 3 birds \& Birds "eaten" & & \\
\hline Surviving snakes \& birds after Round 3 & & \\
\hline Additional Snakes $\&$ Birds for Round 4 & & \\
\hline Snakes \& Birds for Round 4 & & \\
\hline Snakes "eating" < 3 birds \& Birds "eaten" & & \\
\hline Surviving snakes $\&$ birds after Round 4 & & \\
\hline Additional Snakes \& Birds for Round 5 & & \\
\hline Snakes \& Birds for Round 5 & & \\
\hline Snakes "eating" < 3 birds \& Birds "eaten" & & \\
\hline Surviving snakes $\&$ birds after Round 5 & & \\
\hline Additional Snakes \& Birds for Round 6 & & \\
\hline Snakes \& Birds for Round 6 & & \\
\hline Snakes "eating" < 3 birds \& Birds "eaten" & & \\
\hline Surviving snakes $\&$ birds after Round 6 & & \\
\hline Additional Snakes \& Birds for Round 7 & & \\
\hline Snakes \& Birds for Round 7 & & \\
\hline Snakes "eating" < 3 birds \& Birds "eaten" & & \\
\hline Surviving snakes $\&$ birds after Round 7 & & \\
\hline Additional Snakes \& Birds for Round 8 & & \\
\hline Snakes \& Birds for Round 8 & & \\
\hline Snakes "eating" < 3 birds \& Birds "eaten" & & \\
\hline Surviving snakes $\&$ birds after Round 8 & & \\
\hline Additional Snakes \& Birds for Round 9 & & \\
\hline Snakes \& Birds for Round 9 & & \\
\hline Snakes "eating" < 3 birds \& Birds "eaten" & & \\
\hline Surviving snakes $\&$ birds after Round 9 & & \\
\hline Additional Snakes \& Birds for Round 10 & & \\
\hline Snakes \& Birds for Round 10 & & \\
\hline Snakes "eating" < 3 birds \& Birds "eaten" & & \\
\hline Surviving snakes \& birds after Round 10 & & \\
\hline
\end{tabular}

Surviving snakes = Snakes - Snakes "eating" $<3$ birds

Surviving birds = Birds - Birds "eaten"

Additional snakes $=1$ snake if any survived

Additional birds = $1 / 2$ (Surviving birds); round "half" birds up 


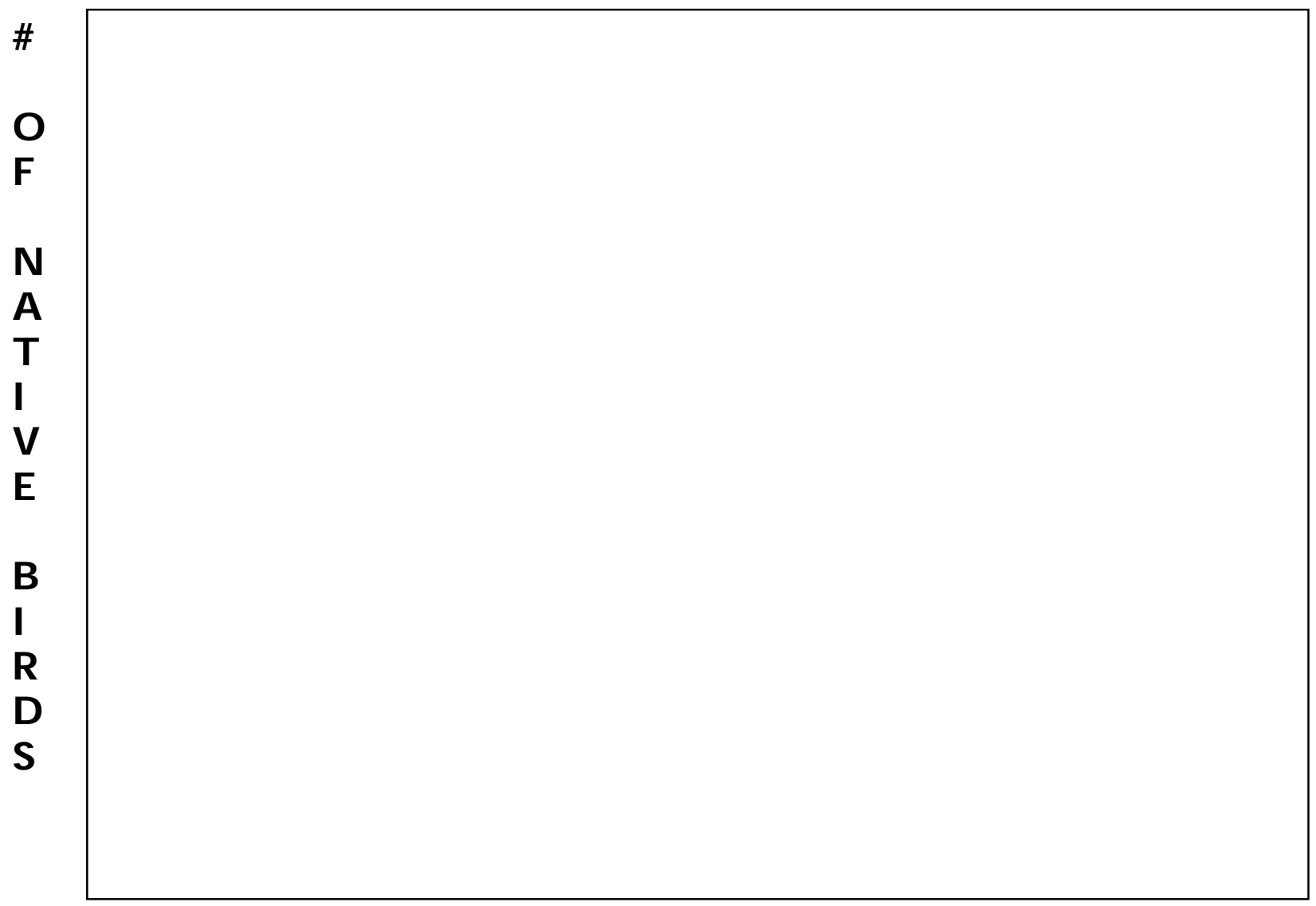

TIME (\# OF ROUNDS) 


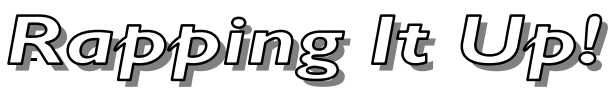

1. After one round, was there a significant effect on the population of native birds? After which round was at least $50 \%$ of the native bird population removed?

2. Using the results from your activity, summarize how the introduction of brown tree snakes impacts native species over time.

3. How do you think an abundance of brown tree snakes here in Florida would affect the native wildlife? 


\section{Glossary:}

Eradicate - Eliminate, exterminate, remove.

Invader/Invasive species- A plant or animal that is not native and causes harm, including disrupting natural ecosystems.

Native species - A plant or animal species that originated in a certain place. A species occurring in its natural range. Species that were present in Florida at the time the first Spanish settlers arrived.

Non-native species - A species introduced to a region intentionally or accidentally. 